\title{
Articles
}

\section{$N\left({ }^{2} D\right)$ Product Velocity Mapped Imaging in the VUV Photolysis of Nitrous Oxide at $118.2 \mathrm{~nm}$}

\author{
Bogdan R. Cosofret, H. Mark Lambert, and Paul L. Houston* \\ Deparment of Chemistru and Chemical Biologv. Comell Chiversitw. Ithaca. New Yom 14853, USt \\ Received December 18, 2001
}

\begin{abstract}
Resonance-enhanced multiphoton ionization with time-of-flight product imaging of the $\mathrm{N}(-\mathrm{D})$ atoms has been used to study the $\mathrm{N}_{2} \mathrm{O}$ photodissociation at $118.2 \mathrm{~nm}$ and the two-photon dissociation at $268.9 \mathrm{~nm}$. These inaging experiments allowed the determination of the total kinetic energy distributions of the $\operatorname{NO}\left(X^{2} \Pi\right)$ and $\mathrm{N}\left(\hat{}^{-} \mathrm{D}_{\mathrm{s}}\right)$ products. The $\mathrm{NO}\left(\mathrm{X}^{\wedge} \Pi\right)$ fragments resulting from the photodissociation processes are produced in highly vibrationally excited states. The two-photon photodissociation process yields a broad $\operatorname{NO}\left(X^{-} \Pi\right)$ vibrational energy distribution, while the 118.2 num dissociation appears to produce a vibrational distribution sharply peaked at $\mathrm{NO}(\mathrm{X} \wedge \bar{\wedge} . v=14)$.
\end{abstract}

Keywords : VUV photolysis. Nitrous oxide. NO vibrational energy distribution. $118.2 \mathrm{~nm}$.

\section{Introduction}

Nitrous oxide plays an important role in the global nitrogen cycle and it is an important trace component of the atmosphere. ${ }^{1}$ The vacuum ultraviolet (VUV) photolysis of nitrous oxide has been extensively studied. ${ }^{2}$ Dissociation of $\mathrm{N}=\mathrm{O}$ in this spectral region has proven to be a good source for various electronically excited states, including $O\left({ }^{1} \mathrm{D}\right)$. $\mathrm{O}\left({ }^{1} \mathrm{~S}\right), \mathrm{N}\left({ }^{+} \mathrm{P}\right.$ and $\left.{ }^{2} \mathrm{D}\right) . \mathrm{N}_{2}\left(\mathrm{~A}^{3} \Sigma^{+}{ }_{\mathrm{u}}\right)$. Much less information is known about either the quantum yields for these excited states $^{2}$ or the energy partitioning in the diatomic fragments. This type of information is needed for a better understanding of the dynamics and the potential energy surfaces of $\mathrm{N}_{2} \mathrm{O}$.

In the $118.2 \mathrm{~nm}$ region $\mathrm{N}_{2} \mathrm{O}$ has an absorption coefficient of about $1000 \mathrm{~atm}^{-1} \mathrm{~cm}^{-1} .3$ At this wavelength. dissociation to $\mathrm{NO}$ and $\mathrm{N}$ fragments primarily produces $\mathrm{NO}\left(\mathrm{X}^{-} \mathrm{-}\right)$ in coincidence with either $\mathrm{N}\left({ }^{+} \mathrm{S}\right)$. $\mathrm{N}\left({ }^{-} \mathrm{D}\right)$, or $\mathrm{N}\left({ }^{-} \mathrm{P}\right)$. The $\mathrm{NO}\left(\mathrm{A}^{-} \Sigma^{-}\right)$ $+\mathrm{N}\left({ }^{4} \mathrm{~S}\right)$ channel is also energetically feasible.

Black et $\mathrm{Cl}^{2}$ measured the quantun yields for the production of $\mathrm{N}_{2}\left(\mathrm{~A}^{3} \Sigma^{-}{ }^{-}\right), \mathrm{N}\left({ }^{3} \mathrm{D}\right)$, and $\mathrm{O}\left({ }^{1} \mathrm{~S}\right)$ from the VUV photolysis of $\mathrm{N}_{2} \mathrm{O}$. The quantum yield of $\mathrm{N}\left({ }^{-} \mathrm{D}\right)$ was measured using the intensity of $\mathrm{NO} \beta$ bands generated by the sequence

$$
\begin{aligned}
& \mathrm{N}\left({ }^{-} \mathrm{D}\right)+\mathrm{N}_{\Sigma} \mathrm{O} \rightarrow \mathrm{N}_{\Sigma}+\mathrm{NO}\left(\mathrm{B}^{\wedge} \Pi_{\mathrm{T}}\right) . \\
& \mathrm{NO}\left(\mathrm{B}^{2} \Pi_{\mathrm{r}}\right) \rightarrow \mathrm{NO}\left(\mathrm{X}^{2} \Pi_{\mathrm{f}}\right)+\mathrm{h} v(\mathrm{NO} \beta \text { bands }) .
\end{aligned}
$$

These authors found that the quantum yield for $N\left({ }^{2} \mathrm{D}\right)$ is about $40 \%$ in the $118 \mathrm{~nm}$ region, but that it drops sharply around $120 \mathrm{~nm}$ where the production of $\mathrm{O}\left({ }^{1} \mathrm{~S}\right)+\mathrm{N}_{2}$ begins to dominate. This observation is also in agreement with that of Nee et $a I^{4}{ }^{4}$ who detected $\left.O{ }^{1} S\right)$ metastable atoms produced in the photodissociation of $\mathrm{N}_{2} \mathrm{O}$ by observing the fluorescence of the $O\left({ }^{1} S \rightarrow{ }^{l} D\right)$ transition. The van der Waals interaction of Xe buffer gas with the metastable oxygen atoms greatly enlianced the normally weak fluorescence. Nee $e t a t^{4}$ observed a strong $O\left({ }^{1} S\right)$ fluorescence for wavelengths greater than $120 \mathrm{~nm}$ and also measured the absorption spectrum of nitrous oxide over the range $100-140 \mathrm{~nm}$. Above $120 \mathrm{~nm}$. the spectrum is nearly a smooth continum, whereas below $120 \mathrm{~nm}$, it is dominated by a single peak at $117.8 \mathrm{~nm}$. The authors attributed this peak to a Rydberg state which dissociates to produce only very small amounts of $O\left({ }^{\prime} S\right)$. In agreement with the previous work by Black et $a l^{2}$. this state is observed to produce strong NO $\beta$ band fluorescence. ${ }^{4}$ The Rydberg state has either ${ }^{1} \Sigma$ or ${ }^{1} \Pi$ symmetry, and states of either symmetry would correlate to $\mathrm{N}\left({ }^{2} \mathrm{D},{ }^{3} \mathrm{P}\right)+\mathrm{NO}\left(\mathrm{X}^{3} \Pi\right)$ or $\mathrm{N}_{2}(\mathrm{X})+\mathrm{O}\left({ }^{1} \mathrm{~S}\right)$ products. ${ }^{4,}, 6$ Since Nee et $a l^{+}$observed a very small quantum yield for the production of $O\left({ }^{\prime} S\right)$ atoms, they concluded that the $\mathrm{N}_{2} \mathrm{O}$ Rydberg state must be a major factor in the production of metastable $\mathrm{N}$ atoms.

That this state does indeed produce metastable $\mathrm{N}$ atoms has been shown by the recent work of Umemoto et al. ${ }^{7}$ who investigated the 2-photon photolysis of $\mathrm{N}_{2} \mathrm{O}$ between 235 and $240 \mathrm{um} . \mathrm{N}\left({ }^{2} \mathrm{D},{ }^{2} \mathrm{P}\right)$ and $\mathrm{NO}\left(\mathrm{v}^{\circ}=1\right)$ products were all detected by resonance-enhanced multiphoton ionization (REMPI) combined with TOF mass spectrometry. Efforts were also made to detect $\operatorname{NO}(\mathrm{X} . v=0)$. but the background signal due to the one color MPI process was too great. The authors argued that two processes occur: predissociation of the two-photon excited state of nitrous oxide, and the dissociation of a three-photon excited state into the $N\left({ }^{2} D\right)$ and NO fragments.

Chan $e t a l{ }^{8}$ obtained the electronic excitation spectrum of nitrous oxide along with the corresponding oscillator strengths. In the energy range of $10.36-10.64 \mathrm{eV}$ they find an integrated optical oscillator strength of 0.0523 . The photoabsorption spectrum of $\mathrm{N}_{2} \mathrm{O}$ in the regions $10-12$ and $12.2 \mathrm{leV}$ consists mainly of transitions from the $2 \pi .7 \sigma .1 \pi$ and $6 \sigma$ orbitals to 
Rydberg levels. At 117.8 1un, which corresponds to $10.5 \mathrm{eV}$. the transition is assigned to a $3 \mathrm{p} \pi \leftarrow 2 \pi$, the first member of a Rydberg series leading to an ionization threshold of 10.54 eV.

In this paper we present results for the VUV photodissociation of $\mathrm{N}_{3} \mathrm{O}$ at $118.2 \mathrm{~nm}$, which is nearly resonant with the transition ( $3 \mathrm{p} \pi \leftarrow 2 \pi)$ to a Rydberg state. The VUV radiation was produced by non-resonantly tripling $354.6 \mathrm{~nm}$ laser light in a rare gas cell. We detect the $\mathrm{N}\left(\hat{}^{\mathrm{D}} \mathrm{D}: \mathrm{s}\right)$ product following the primary VUV photolysis

$$
\mathrm{N}_{2} \mathrm{O}+118.2 \mathrm{~nm} \rightarrow \mathrm{N}\left(-\mathrm{D}_{5:}\right)+\mathrm{NO}(\mathrm{X})
$$

using the velocity-mapped, ion imaging technique. The focused ionization laser produces a background of $N\left(-D_{5}\right)$ atoms by a two-photon process:

$$
\mathrm{N}=\mathrm{O}+2 \times(268.9 \mathrm{~nm}) \rightarrow \mathrm{N}\left(-\mathrm{D}_{5 \mathrm{~s}}\right)+\mathrm{NO}(\mathrm{X})
$$

which contributes to the inage. A third process produces a background of $\mathrm{N}^{+}$signal in a multi-photon process involving the $118.2 \mathrm{~nm}$ light. and possibly the $354.6 \mathrm{~mm}$ laser light:

$$
\mathrm{N}_{2} \mathrm{O}+118.2 \mathrm{~nm} / 354.6 \mathrm{~nm} \rightarrow \mathrm{N}^{-}+\mathrm{NO}(\mathrm{X})
$$

By making use of the spatial properties of the imaging technique, we were able to distinguish the primary process of interest from the background contributions.

\section{Experimental Section}

The technique of ion imaging has been described in more detail elsewhere. ${ }^{9}$ Neat $\mathrm{N}_{3} \mathrm{O}$ (Matheson) and $10 \% \mathrm{NO} / \mathrm{He}$ (Matheson) were used from the cylinder without further purification. The gases were expanded at $17 \mathrm{psia}$ through a pulsed $0.5 \mathrm{~mm}$ diameter nozzle and collimated by a $0.5 \mathrm{~mm}$ diameter skimmer mounted $0.5-1.0 \mathrm{~cm}$ from the nozzle orifice. Further downstreant. the molecular beam was crossed at right angles by two counterpropagating laser beams. one used to dissociate the molecules and the other to probe the resulting $\mathrm{N}\left({ }^{-} \mathrm{D}_{2}\right)$ fragments using $(2+1)$ resonanceenhanced multiphoton ionization (REMPI) via the $3 \mathrm{p}^{-2} \mathrm{~S}_{1:}$ state at $268.9 \mathrm{~nm} .{ }^{7}$ Due to the extremely low $\mathrm{N}\left({ }^{2} \mathrm{D}_{5}\right)$ signal in these experiments, the ionization laser was not scanued over the $\mathrm{N}\left(-\mathrm{D}_{3}\right)$ Doppler profile. however the resonance was monitored periodically by detecting $N\left(-{ }^{-} D_{5: 2}\right)$ fragments from the two-photon dissociation of $\mathrm{NO}$ at $268.9 \mathrm{~nm}$.

The dissociation laser radiation at $118.2 \mathrm{~nm}$ was produced by nonresonant tripling in Xe of $354.6 \mathrm{~nm}$ from a Nd:YAG laser. The production of VUV was monitored by detecting the $\mathrm{NO}^{-}$signal from the ionization of $\mathrm{NO}$ at $118.2 \mathrm{lum}$. Power dependence studies showed that the $\mathrm{NO}^{-}$signal levels increased non-linearly with $354.6 \mathrm{~nm}$ pulse energies. with saturation occurring at pulse energies above $45 \mathrm{~mJ}$. Lower laser energies in the range of $25.30 \mathrm{~mJ} /$ pulse were used in the experiments with $\mathrm{N}_{2} \mathrm{O}$ in order to minimize a background signal caused by the $118.2 \mathrm{~nm}$ light. The $354.6 \mathrm{~nm}$ laser light was focused into a cell containing 30 Torr of Xe using a quartz lens of $7 \mathrm{~cm}$ focal length. The output VUV radiation along with the $354.6 \mathrm{~nm}$ light were collinated by a
$\mathrm{LiF}$ lens which served as the exit window of the Xe cell. The $118.2 \mathrm{~nm}$ beam was then focused onto the molecular beam by a $12 \mathrm{~cm}$ focal length $\mathrm{LiF}$ lens located inside the chamber. The $354.6 \mathrm{~nm}$ light was focused some $6 \mathrm{~cm}$ beyond the interaction region.

The tunable light needed to probe the $\mathrm{N}\left({ }^{2} \mathrm{D}_{5:}\right)$ fragments at $268.9 \mathrm{~nm}$ was generated by a $354.6 \mathrm{~nm}$ pumped SCANMATE (Lambda Physik) with Coumarin 540A dye using second harmonic generation in a BBO I crystal. Typical powers were $0.5 \mathrm{~mJ} / \mathrm{pulse}$ with a pulse duration of $8-10 \mathrm{~ns}$. The probe beam was focused using a $\mathrm{MgF}_{2}$ lens with a focal length of $46 \mathrm{~cm}$. The polarization directions of the dissociation and the ionization lasers were parallel and perpendicular to the plane of the detector, respectively:

The inaging technique uses an electrostatic immersion lens which serves to extract the ionized N( $\left.{ }^{-} \mathrm{D}_{3}\right)$ fragments from the interaction region and to focus ions with equal velocity vectors to the same point on the detector. ${ }^{15}$ The magnification factor for this electrostatic lens was measured to be $1.21 \pm 0.03$ by dissociating $\mathrm{NO}$ using 2 photons of $268.9 \mathrm{~nm}$ and probing the $\mathrm{N}\left({ }^{2} \mathrm{D}_{5}\right)$ fragment using the same REMPI scheme as described above. The magnification factor was obtained by comparison of the single ring in the image with the known energetics of $\mathrm{NO}$ dissociating to $\mathrm{N}\left({ }^{\mathrm{B}} \mathrm{D}\right)$ and $\mathrm{O}\left({ }^{2} \mathrm{P}_{\mathrm{J}}\right)$.

The ionized fragments were accelerated into a field-free flight tube along the axis of the molecular beam. The ions were imaged by a position sensitive detector consisting of a chevron-mounted. double microchannel plate (MCP) assembly (Galileo) coupled to a fast phosphor screen. The image on the screen was recorded by a $640 \times 480$ pixel CCD camera (Xybion). Both the MCP and the camera were electronically gated to collect signal corresponding to only the mass of the $\mathrm{N}\left({ }^{2} \mathrm{D}_{5: 2}\right)$ fragment. Signal levels from the $118.2 \mathrm{~nm}$ photodissociation of $\mathrm{N}_{2} \mathrm{O}$ were very low, on the order of $10-20$ ions per frame. We demonstrated that the signal was VUV dependent by pumping out the Xe gas cell and observing that the signal disappeared. There was no contribution to the $\mathrm{N}\left(-\mathrm{D}^{2}:\right.$ ) signal solely from the $354.6 \mathrm{~nm}$ light.

Large background levels were encountered from both the photolysis wavelength $(118.2 \mathrm{~mm})$ and the probe wavelength $(268.9 \mathrm{~nm})$. In order to account for these backgrounds the imaging acquisition consisted of 3 separate toggle states in which the timing between the photolysis and the probe was changed. The first toggle state ensured that the probe laser was delayed from the photolysis by $20 \mathrm{~ns}$. This gave us the desired $\mathrm{N}\left({ }^{-} \mathrm{D}_{5: 2}\right)$ distribution from the photolysis of $\mathrm{N}_{2} \mathrm{O}$ at $118.2 \mathrm{~mm}$ and subsequent ionization of the fragments. The second toggle state accounted for the background caused by $\mathrm{N}_{2} \mathrm{O}$ two-photon absorption of the $268.9 \mathrm{~lm}$ probe laser followed by REMPI ionization of the N( $\left(-D_{5}\right)$. We recorded this background by moving the photoly sis laser pulse to a timing $l \mu$ s after the probe laser pulse. Similarly, the third toggle state accounted for the $118.2 \mathrm{~nm}$ background by removing the probe laser from the time frame of relevance. Each data set was collected for up to a total of 30.000 laser shots. 
Figure 1. Velocity-mapped ion image of the $\mathrm{N}\left({ }^{2} \mathrm{D}_{5: 2}\right)$ tragment detected by $(2+1)$ REMPI at 268.9 nn approxinately 20 ns after photodissociation of $\mathrm{N}_{2} \mathrm{O}$ at $118.2 \mathrm{~nm}$ (toggle state 1 ). The image is the sum of nine datasets totaling 136,980 laser shots.

\section{Results and Discussion}

In these experiments. we have observed signal at mass 14 from a variety of sources. These different sources were distinguished by acquiring inages with both photolysis and probe lasers together and each separately. by toggling the digital delay generator controlling the laser timing. The unique spatial appearance of the intages taken with each laser separately (toggle states two and three: TS2. TS3), provides the basis by which to understand the intage acquired with both lasers together, (toggle state one: TS1), shown in figure 1. The signal acquired in each of the three toggle states depended on the presence of the molecular beam of $\mathrm{N}_{2} \mathrm{O}$. Only a very snall background of ions was produced in the absence of the $\mathrm{N}_{2} \mathrm{O}$ due to interaction of the focused lasers. presumably, with traces of pump oil.

The focused probe laser produced a strong background signal due to detection of the $N(-D)$ product from a twophoton dissociation of $\mathrm{N}_{2} \mathrm{O}$ at the $(2+1)$ REMPI resonance wavelength of $268.9 \mathrm{~lm}$. A power dependence experiment demonstrated a quartic dependence of the $N\left({ }^{-} D\right)$ signal on the laser pulse energy below $1.4 \mathrm{~mJ} / \mathrm{pulse}$ in keeping with the 2 photon dissociation and 2 photon resonance in the REMPI step, and a saturated jonization step. At higher pulse energies. the power dependence was quadratic. indicating that one of the two photon processes became saturated. This background image was acquired with the second toggle state (TS2), when mass 14 signal could only arise from the probe laser. The intensity in the TS2 inlage is concentrated in a central disc approxintately 150 pixels in diameter. and tails off rapidly in pixels beyond this region.

Significant background signal was also produced by the photolysis laser. This background inage was acquired with the third toggle state (TS3) in which mass 14 signal could only arise due to the $354.6 \mathrm{~mm} / 118.2 \mathrm{~mm}$ laser radiation. Although a TOF spectrum showed peaks due to hydrocarbons from interaction with traces of punp oil, the dominant features corresponded to $\mathrm{N}^{+}$. $\mathrm{NO}^{-}$. and $\mathrm{N}_{2} \mathrm{O}^{+}$. This background signal disappeared upon removal of the VUV tripling medium. by pumping out the $\mathrm{Xe}$, indicating a dependence on the 118.2 nim light. Multiphoton absorption processes would be required to ionize $\mathrm{N}_{2} \mathrm{O}$ and its dissociation products: $\mathrm{N}\left({ }^{4} \mathrm{~S}\right.$. $\left.{ }^{-} \mathrm{D},{ }^{-} \mathrm{P}\right)$ and $\mathrm{NO}$. The TS3 background $\mathrm{N}^{-}$image uniformly covers the detector surface suggesting that there is a very broad range of translational energies available to these dissociation products. consistent with a multiphoton absorption scheme.

The TSl image acquired with both lasers is a composite of the background signals arising from each laser interacting with the molecular beam of $\mathrm{N}_{2} \mathrm{O}$ and the additional $\mathrm{N}\left({ }^{-} \mathrm{D}\right)$ signal from the single photon dissociation of $\mathrm{N}_{2} \mathrm{O}$ at 118.2 num. The TSI image thus shows a bright central region and a diffuse, uniform outer coverage extending to the edge of the detector. The additional signal arising from both lasers together is seen as a brighter image intensity in the central region for TSl than TS2. Unlike the background contributions. this additional signal is crucially dependent upon the spatial overlap between the two focused laser beams. The overlap was demonstrated when the central region of the $\mathrm{N}^{+}$image increased significantly more than the sum of either laser background at a particular (x.y) position of a laser focusing lens, but dropped to background levels at different lens positions to the left or right, up or down.

The extra signal due to $\mathrm{N}_{2} \mathrm{O}$ dissociation at $118.2 \mathrm{~nm}$ was weak and was not apparent on every laser shot. It was practical to acquire only about 9000 laser shots in each of the three toggle states before the overlap deteriorated. Individual images were shifted to a common center, then added to make up the inage seen in Figure 1 , as well as the images corresponding to the TS2 and TS3 toggle states. Matlab routines were used to perform an inverse Abel transform so as to obtain the 3-dimensional velocity distribution. Separation of the velocity distribution into angular and speed components

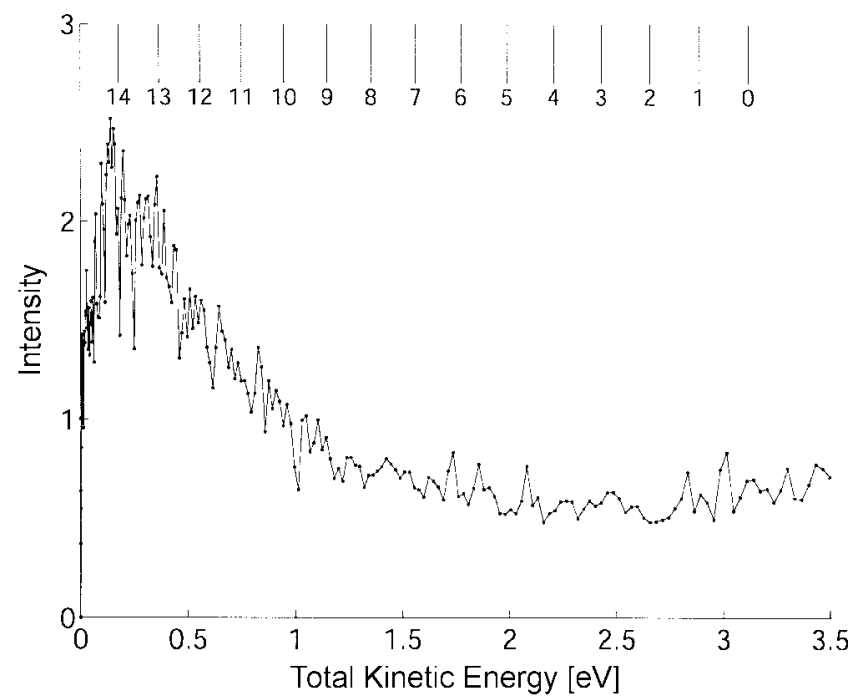

Figure 2. Total kinetic energy distribution of $\mathrm{N}\left({ }^{2} \mathrm{D}_{5: 1}\right)+\mathrm{NO}(\mathrm{X})$ obtained after the inverse Abel transformation of the image displayed in Figure 1 , which was recorded in toggle state 1 (both lasers present). 


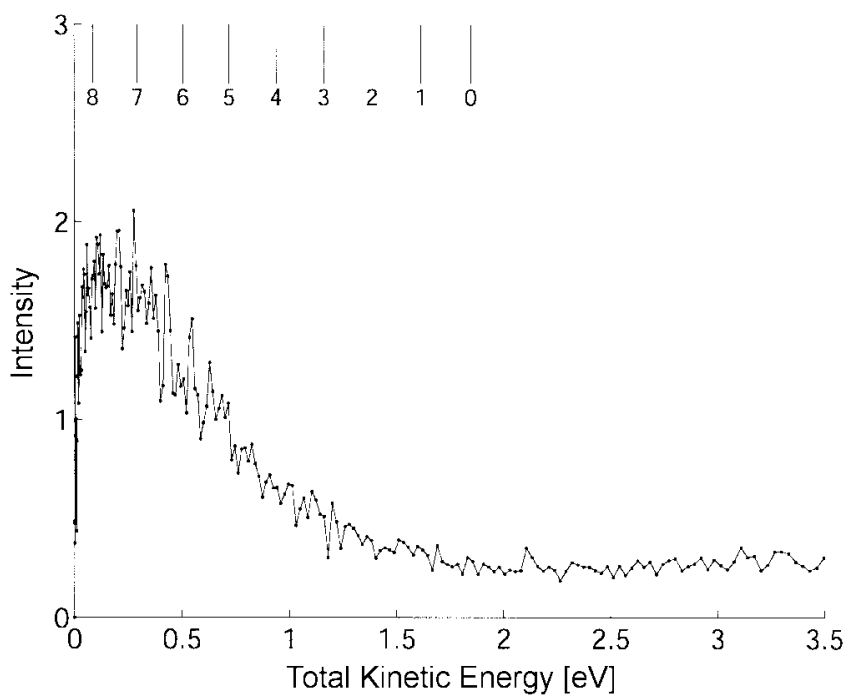

Figure 3. Total kinetic energy distribution of $N\left({ }^{2} D \leq:\right)+N O(X)$ obtained after the inverse Abel transfonation of the background inage recorded in toggle state 2 (268.9 nun REMPI probe laser only).

was achieved by integrating over speed intervals for each angle. and similarly integrating over all angles for each speed. The distribution of total kinetic energy released for the dissociation chamuel leading to $\mathrm{N}$ and $\mathrm{NO}$ cofragments was obtained by using the conservation laws of energy and momentum for each toggle state, and correcting for the magnification factor of our ion collection optics.

The total kinetic energy distributions derived from the sumuned images for each toggle state are shown in Figure 2 (TS1), Figure 3 (TS2), and Figure 4 (TS3). The broad. flat appearance of the kinetic energy distribution for the photolysis laser background (TS3), reflects the uniform inage intensity extending to the perimeter of the detector surface.

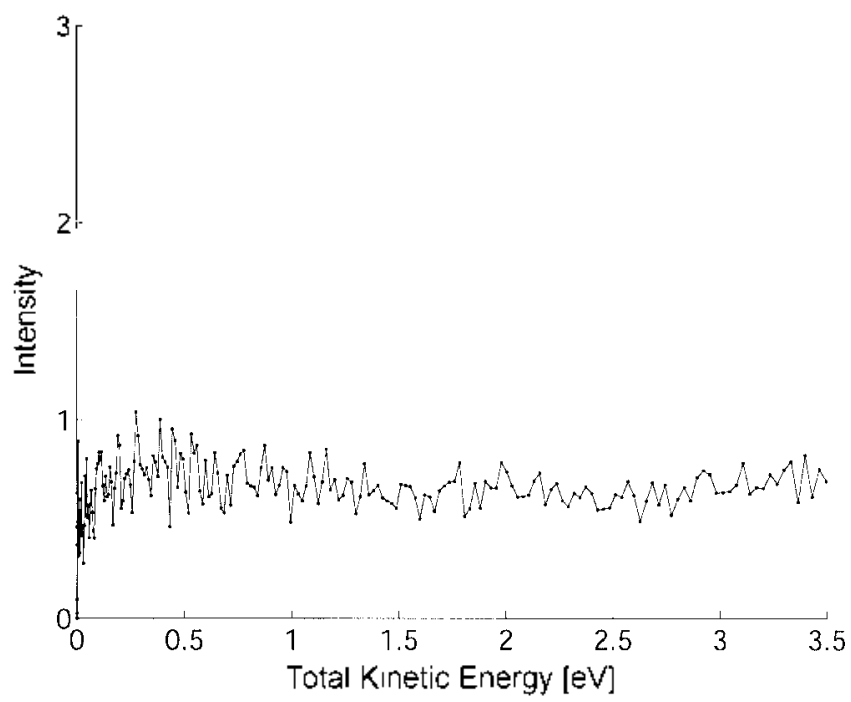

Figure 4. Total kinetic energy distribution of $N\left({ }^{2} D_{5: 2}\right)+N O(X)$ obtained after the inverse Abel transfonmation of the background inage recorded in toggle state $3(118.2 \mathrm{~mm} / 354.6 \mathrm{~nm}$ photolysis laser onlv).
This background from the photolysis laser contributes a pedestal-like appearance to the kinetic energy distribution derived from the image acquired with the photolysis and probe lasers (TS1). This is most apparent in Figure 2 as the non-zero baseline at kinetic energies above $1.5 \mathrm{eV}$. Since the kinetic energy distributions for TSI and TS3 are obviously the same in this region, it is reasonable to assume that the separation of the photoly sis laser background contribution to TSl should be a simple matter of subtraction.

The kinetic energy distribution corresponding to TS2 provides infonmation about the internal energy distribution of the NO co-fragment from the two-photon dissociation of $\mathrm{N}_{2} \mathrm{O}$ at $268.9 \mathrm{~mm}$. The difference between the two-photon energy of the laser radiation and the $\mathrm{N}_{2} \mathrm{O}$ dissociation energy to give $\mathrm{N}\left({ }^{\prime} \mathrm{D}\right)+\mathrm{NO}$ products is the available energy to be partitioned between the kinetic energy of the recoiling cofragments and the internal energy of the NO diatom. The comb appearing above the data plotted in Figure 3 indicates the NO vibrational level corresponding to the difference between the known available energy and the observed kinetic energy. The right hand side of the comb marks the maximum energy available to translational motion and thus correlates with vibrationless. rotationless $\mathrm{NO}(1=0)$. In agreement with the energetics. the observed kinetic energy distribution has little intensity past the maximum allowed energy. The inferred vibrational distribution is inverted. peaking at $\mathrm{NO}(1=7)$. Previous two-photon dissociation studies at shorter wavelengths between 235 and $240 \mathrm{~lm}$ did not provide vibrational distributions because only $N O(v=1)$ was detected. ${ }^{7}$

The contribution of the probe laser induced background is not so easily separated from the two-laser contribution in TSl as was the photolysis laser background. A simple consideration of the relative intensities in Figures 2-4 will show that the kinetic energy distributions corresponding to TS2 and TS1-TS3 are comparable in magnitude and that further subtraction of TS2 would result in near zero or even negative intensities. This is likely a consequence of the competitive nature of the two multi-photon processes involving the probe laser, and we should expect that the probe laser background determined without the photolysis laser (TS2), will be reduced somewhat in the presence of the competing two-laser pump/probe process (TS1). By constraining the kinetic energy distributions TS1-f*TS2 to be equal to TS3, we could estimate the factor " $\mathrm{f}$ ", by which the probe laser background should be reduced, and thus obtain the kinetic energy distribution for the two laser process alone.

Even without explicitly correcting for the probe laser background. it is clear from a comparison of the kinetic energy distributions (see Figures 2-4). that there is a significant peak near $0.14 \mathrm{eV}$ which is present only in the case of TSI. This is a reproducible feature in the data sets acquired from day to day. and which emerges more clearly after summing several images. The comb of NO vibrational levels in Figure 2. which correlate with the kinetic energy available to the $\mathrm{N}(-\mathrm{D})$ and NO products, indicates that the peak corresponds to $\mathrm{NO}(v=14)$. Although there are no available calculations or experimentally derived bond lengths for the 10.5 
eV Rydberg states of $\mathrm{N}_{2} \mathrm{O}$. it appears likely that the $\mathrm{NN}--\mathrm{O}$ bond is severely compressed or extended in the excited state of $\mathrm{N}_{2} \mathrm{O}$ in order to create such high vibrational excitation in the NO photofragment.

The peak value of the total kinetic energy of $0.14 \mathrm{eV}$ corresponds to a lab frame velocity of $1133 \mathrm{~ms}^{-1}$ for the probed N( $\left.{ }^{\circ} \mathrm{D}\right)$ fragment. The Doppler width (full width at half maximum) for the REMPI transition under these conditions works out to be about $0.47 \mathrm{~cm}^{-1}$. The nominal bandwidth of the dye laser is quoted by the manufacturer to be $0.15 \mathrm{~cm}^{-1}$ in the fundamental. It is our experience that the bandwidth after second harmonic generation is increased by a factor of two. Since the REMPI transition is a two-photon absorption in the resonance step. the laser bandwidth will further increase by a factor of $\sqrt{2}$. The effective laser bandwidth in the VUV nay thus be estimated as $0.42 \mathrm{~cm}^{-1}$. It is clear from these bandwidth considerations that our experiment was somewhat biased towards less efficient detection of $\mathrm{N}\left({ }^{\circ} \mathrm{D}\right)$ photofragments with velocities faster than at the peak of the kinetic energy distribution. Due to the weak signal. however. and the long accumulation times, it was deemed more practical to keep the probe laser wavelength on resonance rather than to scan over the full Doppler profile

The very nearly isotropic appearance of the intages indicates that the beta parameter is small. with analysis giving a value on the order of 0.1 for the peak of the kinetic energy distribution derived from TSI. This nearly zero anisotropy parameter indicates that the timescale for dissociation must be comparable to or slower than the rotational period. The shape of the angular distribution for the two photon dissociation of $\mathrm{N}_{2} \mathrm{O}$ at $268.9 \mathrm{~nm}$ showed a significant contribution from the $\mathrm{P}_{4}(\cos \theta)$ Legendre polynomial, as is expected for a two photon absorption.

\section{Conclusion}

$N\left({ }^{A} D_{5: 2}\right)$ fragments have been detected from the photo- dissociation of $\mathrm{N}_{2} \mathrm{O}$ at $118.2 \mathrm{~mm}$ and from the two-photon dissociation at $268.9 \mathrm{~nm}$ using the velocity-mapped, ion imaging technique. The total kinetic energy distributions for the products $\mathrm{N}\left({ }^{-} \mathrm{D}\right)$ and $\mathrm{NO}(\mathrm{X})$, derived from analysis of the images and the conservation laws. indicate that the $N O(X)$ co-fragments appear to have inverted vibrational distributions for both processes. Remarkably, the $118.2 \mathrm{~nm}$ photodissociation produces a dominant peak in the total kinetic energy distribution corresponding to $\mathrm{NO}(v=14)$. In the 2-photon dissociation at $268.9 \mathrm{~nm}$, the NO product was observed to have a broader vibrational distribution spread over several levels near to the energy limit.

Acknowledgment. It is a pleasure to acknowledge the partnership of Prof. Kyung-Hoon Jung on projects using product imaging. His work in this area and the students he has trained have made major contributions to the field. We thank Nathan Emmott for his help in these experiments. This research was supported by the DOE under grant DE-FG-288ER I3934.

\section{References}

1. Trogler, W. C. Crit Rev Anal Chem 1999, 28.433-437.

2. Black. G.: Sharpless. R. L.: Slanger. T. G.: Lorents. D. C. J. Chent Phos 1975. 62.4266-4273.

3. Okabe. H. Photochemistry of Small Molecules: John Wiley \& Sons: Toronto, 1978.

4. Nee, J. B.: Yang. J. C.: Lee. P. C.; Wang. X. Y; Kuo, C. T. J. Plys. B: At. Afol. Opt. Phus 1998, 31.5175-5181.

5. Patsilinakou. E.: Wiedmant1. R. T.: Fotakis. C.: Grant. E. R. J. Chent. Phs 1989.91.3916-3925.

6. Hopper. D. G. J. Chem. Phws. 1984. $80.4290-4316$.

7. Umemoto. H: Kashiwazaki. M.; Yahata. T. J. Chem. Soc. Faraday Trans. 1998, 94, 1793-1795.

8. Chan, W. F.: Cooper, G.: Brion. C. E. Chem. Phus. 1994, 180, 77 88

9. Wilsont. R. T.: Mueller. I. A.: Houston. P. L. J. Phos Chent A 1997. 101. 7593-7599.

10. Eppink. A. T. J. B.: Parker, D. H. Rev Sci. Instrum 1997, 68. 3477-3484. 